\title{
VALORAÇÃO DAS AMENIDADES URBANAS: UMA ESTIMAÇÃO A PARTIR DOS DIFERENCIAIS SALARIAIS E DO CUSTO DE HABITAÇÃO PARA AS REGIÕES METROPOLITANAS BRASILEIRAS $\left({ }^{*}\right)\left({ }^{* *}\right)$
}

\author{
Roberta de Moraes Rocha $a^{a}$ \\ André Magalhães ${ }^{b}$
}

RESUMO: Seguindo a linha dos estudos que objetivam valorar as amenidades urbanas, o presente artigo se propôs a aplicar uma abordagem, alternativamente à hedônica, para levantar evidências da qualidade de vida das regiões metropolitanas brasileiras. Dessa forma, a abordagem da preferência revelada (Kahn, 2005) foi aplicada para ordenar as regiões metropolitanas em relação à qualidade de vida ofertada, supondo que os diferencias da remuneração do trabalho e do custo com a habitação, que tendem a persistir entre as regiões de um país, informam sobre a qualidade das amenidades ofertadas por elas. Baseando-se nessa hipótese, o ranking estabelecido, de acordo com Kahn (1995), a partir do salário nominal e do aluguel nominal, indicou a seguinte ordenação das regiões metropolitanas com respeito à qualidade de vida: Belém, São Paulo, Rio de Janeiro, Recife, Salvador, Porto Alegre, Fortaleza, Curitiba, Belo Horizonte.

PALAVRAS-CHAVE: Valoração amenidades; qualidade das amenidades; índice de qualidade vida.

CLASSIFICAÇÃO JEL: R13; R23.

\footnotetext{
Artigo recebido em 26/08/2011 e aprovado em 24/01/2013.

" Este trabalho foi desenvolvido com apoio do CNPq.

a Doutora em Economia pelo Programa de Pós-Graduação em Economia da Universidade Federal de Pernambuco (PIMES/UFPE) e professora do Departamento de Economia da UFPE, campus do Agreste. Contato: roberta_rocha_pe@yahoo.com.br.

${ }^{\text {b }}$ Ph.D em Economia pela Universidade de Illinois e professor do Departamento de Economia da UFPE. Contato: magalhoes@decon.ufpe.br.
} 


\title{
VALUATION OF URBAN AMENITIES: ESTIMATES BASED ON WAGE AND HOUSING PRICE DIFFERENTIALS FOR BRAZILIAN METROPOLITAN REGIONS
}

\begin{abstract}
This paper applies an empirical approach to estimate the quality of life in Brazilian metropolitan areas which is alternative to the hedonic approach. The revealed preference approach (Kahn, 2005) was applied to obtain evidences of the quality of life in metropolitan regions, assuming that the differences in wages and costs of housing, which tend to persist among the regions of a country, reveal the quality of the amenities offered by those regions. Based on that assumption, a ranking of metropolitan areas with respect to quality of life was structured based on nominal wage and rent roll and according to Kahn (1995): Belém, São Paulo, Rio de Janeiro, Recife, Salvador, Porto Alegre, Fortaleza, Curitiba, Belo Horizonte.
\end{abstract}

KEYWORDS: Amenity valuation; quality of amenities; life quality index. 


\section{INTRODUÇÃO}

As regiões que integram um país são caracterizadas por especificidades geográficas, climáticas, econômicas e sociais, as quais podem atuar como fatores de aglomeração, no caso das amenidades - atraindo os agentes produtivos em busca de uma qualidade de vida melhor -, ou de dispersão, se atuarem como “amenidades negativas”. Essas forças de aglomeração ou dispersão podem variar em intensidade, a depender do grau da heterogeneidade das regiões que compõem o país.

Nesse contexto, tendo como referência países como o Brasil - com extensa área territorial, integrado por regiões que possuem diferentes tipos de clima, características geográficas e ambientais, além das significativas disparidades econômicas e sociais que imperam - é razoável esperar que algumas regiões sejam mais atrativas para se morar do que outras. Desse modo, é intuitivo supor que os trabalhadores ao fazerem uma escolha locacional levem em consideração tanto as oportunidades econômicas ofertadas por cada região quanto os demais fatores não econômicos que influenciam a sua função de bem estar.

Esse trade off, entre as oportunidades econômicas e as amenidades locais, que condicionam a decisão de migração dos trabalhadores, é a base de argumentação das abordagens que objetivam valorar as amenidades a partir de modelos de escolhas locacionais (Rosen, 1974 e 1979; Roback, 1980 e 1982). Um método que tem sido amplamente aplicado para a valoração das amenidades locais é o hedônico (Rosen, 1974 e 1979; Roback, 1980 e 1982), o qual se baseia na ideia de que, se um atributo local representar uma amenidade negativa para os trabalhadores, deve se esperar que os trabalhadores sejam compensados com um maior salário e um menor custo de moradia para viver nas regiões que apresentam uma maior dotação desse atributo. Assim sendo, o valor que os consumidores estão dispostos a pagar pelos atributos locais, a partir do modelo de Roback (1982), é estimado com base na equação dos salários - o salário dos trabalhadores é regredido em função de suas características e dos atributos locais - e na equação hedônica dos aluguéis - o aluguel pago pelos trabalhadores $\left(r_{i j}\right)$ é regredido em função dos atributos dos imóveis e dos atributos locais. Roback (1982), portanto, a partir da propensão marginal a pagar por cada atributo local que influencia a função de utilidade dos trabalhadores, propõe uma medida para avaliar a qualidade das amenidades das regiões, o qual nomeia de "índice de qualidade de vida local"1.

Contudo, o cálculo do índice de qualidade de vida proposto por Roback (1982) depende da disponibilidade de dados de amenidades que influenciam a função de bem

\footnotetext{
${ }^{1}$ Ver no Apêndice A.1 a fórmula matemática do índice de qualidade de vida proposto por Roback (1982).
} 
estar dos consumidores e que muitas vezes não são mensuráreis ou não estão disponíveis para o pesquisador. Buscando contornar esta limitação, Kahn (1995) propõe uma forma alternativa para valorar as amenidades e ordenar as regiões em relação à qualidade desses atributos a qual não depende da observação desses dados. Assim como Roback (1982), assume que a persistência dos diferencias salariais e do custo com a habitação entre as regiões - em uma situação de equilíbrio em que os trabalhadores não teriam ganhos de bem estar com a migração - é reflexo da heterogeneidade que caracterizam as regiões, em relação as suas dotações das amenidades. Supondo que os diferencias da remuneração do trabalho e do custo com a habitação, que tendem a persistir entre as regiões de um país, informam sobre a qualidade das amenidades que as caracterizam, Kahn (1995) calcula um índice de qualidade de vida com base no percentual de trabalhadores que teriam um aumento no salário e uma redução no preço do aluguel se migrassem para regiões diferentes das que moram.

Seguindo Kahn (1995), o presente artigo, a partir das estimações das equações de diferencial salarial e do custo de habitação, constrói um indicador que mensura a qualidade das amenidades das regiões metropolitanas brasileiras (RM) e ordena as RM com respeito à sua qualidade de vida. Esse indicador baseia-se da hipótese de que não apenas as características dos trabalhadores, mas também seu estoque de capital humano e o setor de ocupação, entre outras características, explicam os diferencias salariais regionais. Considera-se, portanto, que apenas uma parcela do salário dos trabalhadores é explicada por suas características, e a parte residual do salário - que não é possível explicar por suas características - é atribuída a fatores associados às regiões.

Neste artigo, este resíduo é utilizado como um indicador de qualidade das amenidades locais. Do mesmo modo, é suposto que parte do custo de habitação das regiões é explicada por fatores locais, após considerar a contribuição dos atributos dos imóveis no preço do imóvel. De fato, tomando como exemplo as regiões metropolitanas brasileiras, Azzoni e Servo (2002) encontram evidências de que os diferenciais de renda entre os trabalhadores residentes nas regiões metropolitanas brasileiras ainda permanecem significativos, após descontar (controlar) a contribuição das características dos trabalhadores e do custo de vida das regiões nos diferenciais salariais. Esse resíduo salarial, portanto, pode ser atribuído a fatores locais associados às regiões metropolitanas e pode ser utilizado como um indicador da qualidade de vida local.

A seguir, no item 2, apresentam-se algumas evidências empíricas, para o Brasil, da importância das amenidades para a função de bem estar dos consumidores. No item 3 explica-se com mais detalhes como é obtido o indicador que avalia a qualidade das amenidades locais, a partir da estimação das equações dos diferenciais compensatórios 
dos salários e dos aluguéis. $\mathrm{O}$ item 4 destina-se à construção do índice de qualidade de vida proposto por Kahn (1995). Em seguida, o item 5 contém informações sobre a base de dados utilizada no exame empírico e especificam-se as equações empíricas dos salários e dos aluguéis. A análise dos resultados é objeto do item 6 e as considerações finais, do item 7 .

\section{EVIDÊNCIAS EMPÍRICAS DA RELAÇÃO ENTRE BEM ESTAR E AMENIDADES LOCAIS}

Para o Brasil ainda são incipientes as pesquisas empíricas que objetivam valorar as amenidades locais com um enfoque regional. Ainda mais escassos são os estudos que unem os dois setores, o de trabalho e o habitacional, para inferir sobre o valor que as pessoas estão propensas a pagar pelas amenidades. Porém, estudos localizados, realizados para o mercado habitacional de algumas cidades brasileiras, têm contribuído para o debate em torno da importância que representa a vizinhança onde o individuo reside para a sua função de utilidade.

Nesse sentido, Herman e Haddad (2005) obtêm evidências da contribuição marginal das amenidades urbanas para o preço dos imóveis residenciais da região metropolitana de São Paulo. O método de estimação adotado é o hedônico (Rosen, 1974), e os autores utilizaram a construção de fatores principais para minimizar o efeito da multicolinearidade presente nos dados. O exame é realizado a partir de uma amostra de 497 imóveis da base de dados da Pesquisa Orçamento Familiar (POF), da Fundação Instituto de Pesquisas Econômicas (FIPE), do ano de 1999, georeferenciado pelo endereço de cada domicílio. Os autores exploraram tanto dados de amenidades naturais quanto de amenidades "sociais" e encontram evidências de que os imóveis próximos às estações de trem, de áreas arborizadas e com melhor acesso a serviços de um modo geral tendem a ser mais valorizados, enquanto a criminalidade tem efeito contrário no preço do imóvel.

Mais recentemente, estudos localizados para o mercado habitacional brasileiro têm adotado modelos hierárquicos como alternativas ao modelo clássico de regressão hedônica para a valoração das amenidades (Fávero, 2011). Uma vez que os preços dos imóveis apresentam certa estrutura hierárquica - considerando dois patamares, o preço do imóvel depende dos seus atributos (patamar 1) e da sua localização, da rua (ou bairro) que está situado por exemplo (patamar 2) -, os imóveis que se encontram em uma mesma rua são mais semelhantes que aqueles localizados em ruas diferentes. $\mathrm{E}$ a estimação de equações hedônicas sem considerar essa estrutura de dados pode gerar resultados espúrios pela subestimação dos erros padrão do modelo (Hox, 2002). Utilizando um modelo hierárquico com classificação cruzada, Fávero (2011) investiga a 
importância das características da vizinhança dos imóveis comerciais de São Paulo sobre a formação de seus preços, controlando pelos atributos dos imóveis. A análise baseia-se em uma mostra de 77 imóveis comerciais alugados provenientes de 15 distritos em classificação cruzada com 10 zonas comerciais. Como principal resultado, obtém que apenas $12,8 \%$ da variação total nos preços de aluguel dos imóveis associam-se com as diferenças existentes entre as características dos próprios imóveis, sugerindo que a variação entre o preço dos imóveis da amostra é, em maior parte, explicada por atributos do entorno do imóvel. Além disso, evidencia que imóveis localizados em zonas comerciais com menores taxas de vacância tendem a ser mais valorizados, assim como em distritos com estações de metrô e mais próximos do aeroporto de Congonhas. Por outro lado, quanto mais violento for o distrito, menor deve ser a média dos preços do aluguel.

Com outro enfoque de análise, o mercado de trabalho, Silveira Neto e Azzoni (2004) estimam uma equação tipicamente minceriana dos salários com o objetivo de examinar a influência de algumas amenidades, sociais e naturais, para a persistência dos diferencias de renda entre os residentes nas aéreas urbanas das unidades da federação brasileira. O exame é realizado com base na Pesquisa Nacional por Amostra e Domicílios (PNAD) do ano de 2002. Os autores evidenciam que as regiões Sul e Nordeste estão melhores servidas pelas amenidades incorporadas no exame quando comparadas à região Sudeste; e a região Sudeste estaria melhor, de acordo com esses atributos, que a região Norte e a região Centro-Oeste. Os autores também observam que as diferenças do custo de vida entre as unidades geográficas consideradas na análise explicam parte dos diferenciais regionais nos salários que tendem a persistir entre os trabalhadores.

Explorando ambos os mercados, de trabalho e o habitacional, com base no modelo de Roback (1982), Monte (2004) estima a propensão a pagar pelas amenidades de clima pelos trabalhadores que moram nas regiões metropolitanas brasileiras. $\mathrm{O}$ autor utilizou a Pesquisa de Orçamento Familiar (POF) como fonte das características dos imóveis e dos trabalhadores, e os dados de clima estão reportados no Anuário Estatístico do Brasil do ano de 1987, do IBGE. Os resultados encontrados por Monte (2004) indicaram que o aumento da temperatura média anual e da variação impacta positivamente a função de utilidades dos trabalhadores. Os demais resultados sugerem que os trabalhadores preferem morar nas regiões metropolitanas com menor umidade do ar, com menos horas de sol, e próximas ao mar. Corroborando alguns dos resultados de Monte (2004), Rocha e Matos (2012) também encontram evidências da importância das amenidades naturais para a função de bem estar dos trabalhadores que moram nas regiões metropolitanas brasileiras. Os principais resultados da pesquisa indicam que os trabalhadores estão dispostos a pagar para morar nas RM mais próximas à costa, 
com os maiores índices médios anuais de precipitação, nas RM mais úmidas, e com as maiores temperaturas médias no mês de janeiro. Por outro lado, os trabalhadores devem ser compensados monetariamente para morar nas RM com os maiores índices médios de precipitação no mês de setembro e com as maiores temperaturas médias no mês de julho.

Contudo, para a estimação do índice de qualidade de vida proposto por Roback (1982), de forma que avalie todos os fatores que influenciam a função de bem estar dos trabalhadores, seria necessário que o pesquisador observasse todos eles, o que é pouco provável que aconteça na prática ${ }^{2}$. Portanto, cabe ao pesquisador determinar quais os atributos locais que serão considerados no exame empírico, o que deve depender de cada objetivo de pesquisa. Desse modo, reconhece-se que o índice de qualidade de vida proposto por Roback (1982) é uma medida relativa, que captura apenas a qualidade dos atributos locais que foram considerados na análise pelo pesquisador.

Por sua vez, Kahneman (2000) faz uma análise crítica das tradicionais abordagens para valoração de bens públicos que avaliam o grau de bem estar dos consumidores com base no critério da propensão marginal a pagar. $\mathrm{O}$ autor defende a ideia de que tais abordagens não levam em consideração aqueles fatores que são determinados por experiências vividas em um determinado momento pelo consumidor e que influenciam a sua função de utilidade. $\mathrm{O}$ seu questionamento pode ser resumido na seguinte pergunta: será que a partir da obtenção do valor que os consumidores estão dispostos a pagar pelo consumo das amenidades locais, com base no conceito da propensão marginal a pagar, pode-se intuir se um indivíduo estaria mais feliz se morasse na localidade $i$, alternativamente à localidade $j$ ? Kahneman (2000), portanto, argumenta que para responder essa pergunta é necessário construir uma medida que considere os fatores que influenciam o estado de felicidade do indivíduo, os quais não podem ser capitados por experiências passadas, já que a felicidade do indivíduo é um estado de momento ${ }^{3}$.

Respaldando-se, assim, nas limitações impostas pela abordagem hedônica, Kahn (1995) propõe uma forma alternativa para valorar as amenidades e ordenar as regiões quanto à qualidade desses atributos que não depende da observação desses dados. Entretanto, o autor parte dos mesmos pressupostos do modelo teórico de Roback (1982) e assume que a persistência dos diferencias salariais e do custo com a habitação entre

\footnotetext{
${ }^{2}$ Nessa linha de argumentação, um debate em torno do tema "felicidade humana" vem tomando um crescente espaço na literatura sobre economia do bem-estar ou economia da felicidade (ver, por exemplo, Kahneman, 2000).

${ }^{3}$ É importante salientar que estudos empíricos sobre "felicidade humana" devem se basear em informações primárias, a partir de relatos dos indivíduos sobre o seu estado de felicidade, o que pode representar uma limitação quando o objeto de estudo envolve uma grande amostra.
} 
as regiões, em uma situação de equilíbrio em que os trabalhadores não teriam ganhos de bem estar com a migração, é reflexo da heterogeneidade que caracterizam as regiões, em relação as suas dotações das amenidades.

A seguir apresenta-se o método proposto por Kahn (1995) para a construção de um indicador que avalia a qualidade de vida das localidades.

\section{DERIVAÇÃO DOS DIFERENCIAIS COMPENSATÓRIOS DOS SALÁRIOS E ALUGUÉIS}

A base de argumentação de Kahn (1995), para a obtenção de um indicador que mensura a qualidade das amenidades (ou qualidade de vida) das regiões, tem como referência o modelo de equilíbrio de Roback (1980 e 1982). Contudo, na visão de Kahn (1995), a abordagem da preferência revelada, como denomina o próprio autor, apresenta duas vantagens, em relação à abordagem hedônica, para o estabelecimento de um ranking da qualidade de vida local. A primeira se refere à não dependência da observação dos dados de amenidades, já que essas variáveis não entram no cálculo do "índice de qualidade de vida" de Kahn (1995). Essa é uma vantagem, em comparação à abordagem hedônica, quando os dados dos atributos locais não são observáveis ou não estão disponíveis para o pesquisador. Além disso, ao não incluir as variáveis de amenidades, a abordagem de Kahn (1995) evita os problemas econométricos impostos pela abordagem hedônica - os erros de mensuração das variáveis de amenidades, os problemas das variáveis omitidas e a multicolinearidade entre tais variáveis - que podem estar presentes em tais modelos. Outra vantagem apontada por Kahn (1995) está relacionada com a possibilidade, na abordagem proposta, do salário e do preço do aluguel residencial variar entre as localidades para capturar as diferenças na remuneração do trabalho e do aluguel que podem existir entre as localidades.

Em conformidade ao modelo de Roback (1982), Kahn (1995) assume que os trabalhadores têm preferências idênticas no consumo das amenidades. A função de utilidade indireta ${ }^{4}$ dos trabalhadores depende do salário $(w)$, do preço do aluguel residencial $(p)$, dados os atributos locais $(a)$. Supondo que não há barreiras à migração, a condição de equilíbrio dessa economia consiste em uma situação em que nenhum trabalhador pode aumentar a sua função de utilidade migrando. Supondo essas hipóteses, se um indivíduo receber um salário mais elevado e pagar um aluguel residencial mais baixo em outra região $j$, diferente da que mora, significa que a região onde ele reside está mais bem servida pelas amenidades.

\footnotetext{
${ }^{4}$ Dada a dotação de amenidades $(a)$ na localidade j, o trabalhador representativo escolhe a cesta de bens de consumo $(c)$ e a quantidade da terra residencial $(h)$ que irá consumir sujeito a sua restrição orçamentária. Portanto, a função de utilidade indireta é a função que depende do salário e do custo da habitação, dado a dotação das amenidades da localidade $j$, e assumindo o peço da cesta de bens de consumo como numerário.
} 
Kahn (1995), portanto, supõe que o diferencial do salário e do preço do aluguel entre as localidades é necessário para compensar o indivíduo pelo menor consumo das amenidades e, a partir desses diferenciais, sugere um indicador para avaliar a qualidade de vida ofertada pelas regiões. Nesse sentido, a qualidade de vida nas $j$ localidades deve ser negativamente associada ao percentual de trabalhadores que podem ter um aumento salarial e uma redução no custo da habitação migrando para as $j$ localidades. Ou seja, quanto maior for esse percentual para a localidade $j$, menor deve ser a qualidade de vida nessa localidade, em comparação as demais.

Assim, para computar o índice de qualidade proposto por Kahn (1995) é necessário conhecer o salário que cada indivíduo receberia se morasse nas $j$ localidades diferentes da que mora, além do aluguel que teria que pagar por um imóvel com os mesmo atributos do imóvel onde reside. Kahn (1995), portanto, propõe obter essas informações pela estimação do salário potencialmente ganho em cada localidade $j$ e o aluguel que o trabalhador teria que pagar em duas etapas.

Na primeira etapa, para cada localidade $j$, separadamente, é regredido o salário $(w)$ dos trabalhadores que moram na localidade $j$ em função de suas características e das características do seu trabalho, como segue abaixo:

$$
w_{i}=X_{i} \beta+\eta_{i}
$$

onde $X_{i}$ inclui as características do trabalhador $i$ e do trabalho do trabalhador, o vetor “ $\beta$ ” mensura o peso que cada característica incluída no vetor $X$ tem sobre o salário pago na região $j$, e $\eta_{i}$ é o termo estocástico.

Da mesma forma, é regredido, separadamente para cada localidade $j$, o aluguel residencial ( $r$ ) que cada trabalhador paga na localidade onde mora em função dos atributos dos imóveis, na forma:

$$
r_{i}=Q_{i} \theta+\mu_{i}
$$

onde $Q_{i}$ representa os atributos dos imóveis; o vetor $\theta$ representa o peso que cada atributo do imóvel tem sobre o preço do aluguel na região $j$; ; e $\mu_{i}$ é o termo estocástico.

Na segunda etapa, a partir dos coeficientes obtidos pela estimação da equação dos salários para cada localidade $j$ (equação 1), é estimado o salário potencialmente ganho para cada indivíduo $i$ em cada localidade $j$ ":

$$
\overline{w_{i j}}=X_{i} \overline{\beta_{j}}
$$

onde no vetor $\overline{\beta_{j}}$ estão inclusos os coeficientes estimados de cada característica dos trabalhadores e da ocupação do trabalho incluídos no vetor $X$. O salário que cada indivíduo $i$ receberia se morasse na localidade $j$ é, portanto, dado por $\overline{w_{i j}}$. 
Da mesma forma é previsto o aluguel que cada indivíduo teria que pagar se morasse em uma localidade diferente da que mora:

$$
\overline{r_{i j}}=Q_{i} \overline{\theta_{j}}
$$

onde o vetor $\bar{\theta}_{j}$ inclui os coeficientes dos atributos dos imóveis obtidos pela estimação da equação do aluguel para a localidade $j$ (equação 2). E, $\bar{r}_{i j}$, dado pela equação (4), é o aluguel previsto que cada indivíduo teria que pagar por um imóvel com os mesmos atributos do imóvel no qual reside.

\section{CONSTRUÇÃO DO ÍNDICE DE QUALIDADE DE VIDA A PARTIR DA ABORDAGEM DA PREFERÊNCIA REVELADA (KAHN, 1995)}

Com base nos diferenciais de salário e do preço do aluguel - entre o observado e o estimado - Kahn (1995) propõe uma medida para estabelecer um ranking da qualidade de vida entre as regiões que integram um país. $O$ índice de qualidade de vida proposto pelo autor é obtido a partir do percentual dos trabalhadores que moram nas $j$ localidades e que poderiam aumentar o seu salário e diminuir o aluguel pago migrando para a localidade $j^{5}$. A ideia por trás dessa medida reside na suposição de que, para um trabalhador morar em uma localidade que lhe oferte uma menor "qualidade de vida", deve receber um maior salário e pagar um menor custo de habitação de tal modo que os ganhos econômicos compensem a queda do seu grau de bem estar, derivado de um menor consumo de amenidades.

Assim, quanto maior for esse percentual para uma determinada localidade $j$, menor deve ser a qualidade de vida na localidade, já que os trabalhadores que nela residem devem ser compensados com um maior salário e um menor custo de habitação, comparativamente a outras localidades.

\footnotetext{
${ }^{5}$ Formalmente, considerando uma amostra de " $n$ " localidades com " $k$ " pessoas residindo em cada localidade $j$, o índice de qualidade de vida é calculado pela equação (5):

$$
I Q V_{-} \text {Khan }=\frac{\sum_{i=1}^{k_{I}} 1 *\left(\left(\bar{w}_{i j^{\prime}}-w_{i j}\right)>0\right) * 1\left(\left(\bar{r}_{i j^{\prime}}-r_{i j}\right)<0\right)}{k_{j}}
$$

Dessa forma, se a condição, $1 *\left(\left(\bar{w}_{i j^{\prime}}-w_{i j}\right)>0\right) * 1\left(\left(\bar{r}_{i j^{\prime}}-r_{i j}\right)<0\right)$, for satisfeita, esse produto é igualado a 1 (um), indicando que o indivíduo $i$ poderia aumentar seu salário e diminuir o aluguel pago migrando da localidade (j) para j', caso contrário o produto será igual a zero.
} 
Kahn (1995), contudo, com base na argumentação de Rauch $(1993)^{6}$, reconhece que a medida proposta para a ordenação da qualidade de vida das regiões apresenta uma desvantagem por não considerar o impacto da concentração do capital humano na produtividade do trabalhador. Kahn (1995) defende a ideia de que as localidades onde os trabalhadores apresentam uma escolaridade média superior à média nacional tenderiam a ofertar salários mais elevados e um custo da habitação mais alto, e não necessariamente uma baixa qualidade de vida. Esse efeito pode ser entendido através do modelo de Roback (1982), no caso em que a amenidade influencia positivamente a produção das firmas, atuando como um fator de atração delas. Nesse caso, de acordo com o modelo de Roback (1982), é provável que tanto o salário quanto os aluguéis, nas localidades com elevada concentração de capital humano, sejam mais altos devido aos efeitos aglomerativos do capital humano.

Buscando captar os efeitos da concentração do capital humano na formação dos salários e do preço dos aluguéis, Silveira Neto (2006) propõe uma extensão à medida de Kanh (1995), ao considerar a existência das externalidades produtivas advindas da concentração regional de trabalhadores qualificados, ou de outro atributo local que atue da mesma forma no custo de produção das firmas. Dessa forma, para o estabelecimento do ranking da qualidade de vida, a partir do percentual dos indivíduos que poderiam ter ganhos econômicos com a migração, Silveira Neto (2006) considera, além daqueles considerados por Kahn (1995) - com salário potencial maior e pagando um menor aluguel -, os trabalhadores com ganhos líquidos, cujo salário obtido com a migração superasse $o$ aumento do aluguel ${ }^{7}$.

Para obter a medida proposta por Kahn (1995) e classificar as localidades quanto a sua qualidade de vida, é preciso apenas estimar o salário e o aluguel que cada trabalhador teria se morasse nas localidades diferentes da que mora.

${ }^{6}$ Com base nas evidências empíricas de Rauch (1993).

${ }^{7}$ Formalmente, o índice de qualidade de vida proposto por Silveira Neto (2006) é dado pela equação (6):

$$
I Q V_{-} \operatorname{Mod}=\frac{\sum_{i=1}^{k_{J}} 1 *\left(\left(\bar{w}_{i c}-w_{i j}\right)>0\right) * 1\left(\left(\bar{r}_{i c}-r_{i j}\right)<0\right)}{k_{j}}+\frac{\sum_{i=1}^{K_{I}} 1 *\left(\left(\bar{w}_{i c}-w_{i j}\right)-\left(\bar{r}_{i c}-r_{i j}\right)>0\right) * 1\left(\left(\bar{r}_{i c}-r_{i j}\right)>0\right)}{k_{j}}
$$

onde o primeiro somatório computa o percentual dos trabalhadores com ganhos econômicos, aumento salarial e redução do preço do aluguel, considerados por Kahn (1995), e, no segundo somatório, Silveira Neto (2006) acrescenta os trabalhadores que pagam um maior preço do aluguel na localidade de destino a despeito de o aumento salarial que ele teria nas regiões diferentes da que mora compensar o aumento do preço do aluguel. 


\section{IMPLEMENTAÇÃO EMPÍRICA}

\subsection{BASE DE DADOS}

A base de dados utilizada na pesquisa foi construída a partir da Pesquisa Nacional por Amostra e Domicílios (PNAD) do Instituto Brasileiro de Geografia e Estatística (IBGE), da qual foram extraídos os dados das características e da ocupação dos trabalhadores, e dos atributos dos imóveis do ano de 2006.

A unidade geográfica de análise é a região metropolitana, incluindo as regiões metropolitanas de Belém, Fortaleza, Recife, Salvador, Belo Horizonte, Rio Janeiro, São Paulo, Curitiba e Porto Alegre. A amostra definida para o exame empírico é composta por todos os chefes da família (declarados na PNAD como pessoa de referência da família), que trabalham em atividades não agrícolas, com mais de 15 anos, com algum ganho positivo na semana de referência que foi entrevistado e que mora em imóvel alugado. A amostra final é composta por 5.636 pessoas, a qual, expandida pelo peso da PNAD, representa $4 \%$ da população total das regiões metropolitanas consideradas na pesquisa.

A variável dependente da equação dos salários é a renda mensal derivada do trabalho da pessoa de referência da família, e a variável dependente da equação dos aluguéis é o preço do aluguel pago mensalmente.

Uma etapa importante para a previsão do salário que o trabalhador receberia e do aluguel que teria que pagar se morasse em cada região metropolitana diferente da qual mora é a escolha das variáveis explicativas, das características do trabalhador e da ocupação do trabalho e dos atributos dos imóveis, as quais explicam a formação dos salários e aluguéis, respectivamente. Dessa forma, dois critérios foram utilizados para a escolha das variáveis explicativas. Primeiro, foram escolhidas as características individuais dos trabalhadores e da ocupação do trabalho, e dos atributos dos imóveis seguindo a literatura em torno dos diferencias compensatórios (Rosen, 1974 e 1979; Roback, 1980 e 1982). Além disso, foram consideradas na análise as variáveis de forma que apresentassem o maior poder de explicação do salário e do aluguel observados para cada trabalhador na região metropolitana que reside. Ou seja, foram comparados o salário e o aluguel observado para cada trabalhador na região metropolitana onde reside, com o salário e o aluguel previsto a partir dos coeficientes estimados para a RM onde os trabalhadores moram.

\subsection{MODELO EMPÍRICO}

Como apenas é observado a salário que o trabalhador recebe na localidade em que ele trabalha, para computar o índice de qualidade de vida proposto por Kahn (1995), é estimado o salário que cada trabalhador receberia se trabalhasse nas demais localidades diferentes da que trabalha, com base na equação (7), conforme foi expresso na equação (1): 


$$
\begin{aligned}
& \ln w_{i j}=\beta_{0}+\beta_{1} \text { sexo }+\beta_{2} \text { idade }+\beta_{3} \text { idade }{ }^{2}+\beta_{4} \text { raça }+\beta_{5} \text { estudo }+\beta_{6} \text { tipo } f a m+ \\
& \beta_{7} \text { posição }+\beta_{8} \text { setor }+\mu_{i j}
\end{aligned}
$$

onde a variável dependente é o logaritmo da renda do trabalho do indivíduo $i$ que mora na localidade $j$. As características dos trabalhadores e da ocupação dos trabalhadores definidas para o exame empírico seguem a literatura clássica que objetiva estimar equações de diferenciais salariais (mincerianas). Dessa forma, foram incluídas as seguintes características: uma variável dummy, para o sexo do trabalhador, tomando o valor 1 se o trabalhador é do sexo feminino ( 0 caso contrário); a idade do trabalhador, a idade ao quadrado (idade ${ }^{2}$ ); e uma variável dummy, para "raça”, com o valor 1 se o trabalhador se declarou ser de cor branca e 0 outro caso. Um vetor de variáveis dummies para os anos de estudos (estudo), se o trabalhador tem de 1 a 3 anos de estudos (est1a3), se o trabalhador tem de 4 a 7 anos de estudos (est $4 a 7$ ), se o trabalhador tem de 8 a 10 anos de estudos (est8a10), se o trabalhador tem de 11 a 14 anos de estudos (est11a14), e se o trabalhador tem 15 anos ou mais de estudo (est15mais), em relação aos trabalhadores com menos de 1 ano de estudo (categoria de referência). Foi incluído um vetor de dummies para o tipo de família, casal sem filhos (familia1); casal com todos os filhos menores de 14 anos (família2); casal com filhos menores de 14 anos e de 14 anos ou mais (familia3); mãe com todos os filhos menores de 14 anos (familia4); mãe com todos os filhos de 14 anos ou mais (familia5); mãe com filhos menores de 14 anos e de 14 anos (família6); e mãe e casal sem declaração de idade dos filhos e outros tipos de família; a categoria de comparação é casal com todos os filhos de 14 anos ou mais. E, $\mu_{i j}$, é o erro estocástico.

Também foi incluído um vetor de variáveis dummies para a posição do trabalho principal, se o trabalhador tem carteira assinada (posiçao1); se o trabalhador é funcionário público estatutário ou militar (posição2); se é autônomo (posiçao3); e se é empregador (posiçao4); em relação aos empregados sem carteira assinada e empregados sem declaração de carteira (categoria de comparação). E, variáveis dummies para setor de atividade que o trabalhador está vinculado, o setor da indústria da transformação e outras atividades industriais (setor1); setor da construção (setor2); setor de comércio (setor3); o setor de alojamento e alimentação (setor4); de transporte, armazenagem e comunicação (setor5); de educação, saúde e serviços sociais (setor6); de serviços domésticos (setor7); e outras atividades (setor8); setor referência de comparação é o setor de administração pública.

A equação (7) é estimada para cada localidade $j$, e a partir dos coeficientes obtidos para cada localidade - o qual representa o peso de cada característica do trabalhador 
no salário pago na localidade $j$ - é estimado o salário que cada indivíduo $i$ ganharia se morasse nas demais localidades, conforme expresso na equação (3).

De forma semelhante, para a obtenção do preço do aluguel nas localidades diferentes da que o individuo mora, estima-se a equação (8), a seguir:

$$
\ln r_{i j}=\beta_{0}+\beta_{1} \text { morcom }+\beta_{2} \text { bens }+\beta_{3} \text { napart }+\beta_{4} \operatorname{serv}+\beta_{5} \text { tam }+\eta_{i j}
$$

onde a variável dependente é o logaritmo do valor do aluguel mensal, $r_{i j}$. A equação (8) é composta por uma variável, número de moradores dividido pelo número de cômodos (morcom), que busca captar a influência da densidade do imóvel no preço do aluguel. Um conjunto de variáveis dummies (bens) para a existência de bens no imóvel: se no imóvel tem telefone (fone); máquina de lavar roupas (lavaroupa); microcomputador (microcom); e geladeira (geladeia). A variável napart é igual a 1 se o imóvel não é um apartamento ( 0 caso contrário). No vetor de variáveis "serv" estão inclusas duas variáveis dummies para o acesso de serviços de saneamento, se o imóvel tem acesso à coleta direta do lixo (lixo), e se o imóvel está ligado à rede coletora de esgoto ou pluvial (esgoto). E no vetor de variáveis tam foram incluídos o número de banheiros do imóvel (nbanheiro); o número de cômodos do imóvel (ncomo); e o número de cômodos do imóvel que serve de dormitório. $\mathrm{E}, \eta_{i j}$, é o termo de erro.

A equação (8) é estimada para cada localidade $j$, e a partir dos coeficientes obtidos para cada localidade - o qual representa o peso de cada característica do imóvel no preço do aluguel em $j$ - é estimado o preço do aluguel, da equação (4), que cada indivíduo $i$ teria que pagar um por imóvel com as mesmas características do imóvel que mora.

\section{RESULTADOS}

\subsection{ANÁLISE DESCRITIVA}

Os resultados das estimações das equações (7) e (8), para cada região metropolitana, estão dispostos nas tabelas no Apêndice 2. Estas tabelas apresentam os coeficientes estimados das características dos trabalhadores e do trabalho a partir da equação dos salários (equação 7) e dos atributos dos imóveis com base na equação dos aluguéis (equação 8). A partir desses coeficientes, são estimados o salário que cada trabalhador receberia se morasse em uma RM diferente da que mora e o preço do aluguel que teria que pagar por um imóvel com as mesmas características do imóvel que mora. Então, da comparação desses valores, obtém-se o percentual de trabalhadores que teriam algum ganho econômico com a migração.

Analisando primeiramente os resultados estimados com base na equação dos salários, tem-se que os coeficientes das características dos trabalhadores e da ocupação 
dos trabalhadores são na maioria significantes no nível de 5\%, o que indica que tais variáveis, incorporadas no modelo empírico, são importantes para prever os salários potencialmente ganhos por cada trabalhador em cada região metropolitana diferente da que mora.

Embora o objetivo de pesquisa não seja analisar os diferenciais dos salários, enfatizando a importância das diferenças das características pessoais dos trabalhadores para explicar a persistência dos diferencias salariais, pois para o propósito de pesquisa essas variáveis são apenas controles, cabe relatar alguns resultados a respeito dos coeficientes estimados.

Nesse sentido, os resultados obtidos pela estimação da equação de salários, para cada uma das nove regiões metropolitanas incorporadas na análise, corroboram com as evidências observadas para o mercado de trabalho dessas unidades geográficas. Assim, decorrente das próprias especificidades que caracterizam essas regiões, em relação às características da amostra e da estrutura do mercado de trabalho, notam-se algumas diferenças relativas à magnitude dos coeficientes estimados de algumas características dos trabalhadores e da ocupação do trabalho (ver Tabela A1).

Observados, portanto, os coeficientes estimados das características dos trabalhadores para cada região metropolitana, há indicações de que os trabalhadores que se declaram na PNAD de raça branca têm uma vantagem salarial em relação aos demais trabalhadores. Entretanto, os resultados sugerem que há um maior diferencial salarial positivo em favor dos trabalhadores de cor branca que residem nas RM de Belo Horizonte e de Fortaleza. No outro extremo, está a RM de Belém, seguida da RM de Salvador, com a menor diferenciação salarial entre trabalhadores de cor branca e de outras raças.

A respeito dessa última constatação, em relação à influência da raça dos trabalhadores nos salários pagos nas regiões metropolitanas, esses resultados não confirmam os obtidos Silveira Neto (2006). O autor encontrou evidências de que os trabalhadores de cor branca residentes na região metropolitana de Salvador apresentam maior vantagem salarial em relação aos trabalhadores de raça não branca, quando comparado às demais regiões metropolitanas. Contudo, essa discrepância nos resultados pode ser atribuída a diferenças na amostra dos dois estudos. Por exemplo, enquanto que Silveira Neto (2006) utiliza uma amostra composta apenas por trabalhadores chefes de família do sexo masculino, a presente pesquisa considerou os chefes de família de ambos os sexos, mulheres ou homens. Remetendo a essas diferenças, quando a amostra é filtrada para os trabalhadores do sexo masculino, de fato, é encontrado um resultado semelhante ao de Silveira Neto (2006); a região metropolitana de Salvador passa a ser a região com maior diferença salarial em favor dos trabalhadores de cor branca. Esse resultado sugere que 
há diferenças regionais nas remunerações no mercado de trabalho, com relação à raça e ao sexo dos trabalhadores. Para o caso da região metropolitana de Salvador, onde em torno de $85 \%$ da população se declaram "não branco", essa diferença parece ser ainda maior para os trabalhadores do sexo masculino.

Os resultados estimados também indicam que há diferenças nas remunerações do trabalho, entre os trabalhadores do sexo masculino e do sexo feminino, com uma maior magnitude, a depender da região metropolitana onde o trabalhador reside. Dessa forma, os resultados sugerem que a maior diferenciação salarial, em favor dos trabalhadores do sexo masculino, está na RM de Belém, em ralação às demais RM incorporadas na análise. Contrapondo a essa observação, os resultados sugerem que a região metropolitana que apresenta salários mais igualitários para homens e mulheres, relativamente às demais RM, é a RM do Rio de Janeiro.

As variáveis dummies para os anos de estudo dos trabalhadores também sugerem que também existem diferenças nas remunerações dos trabalhadores, em função do seu grau de escolaridade, entre as nove regiões metropolitanas em análise. Na RM de Belém, está a maior diferença salarial, entre os trabalhadores com o grau de escolaridade mais alto observado, com 15 anos ou mais de estudo, e os trabalhadores com menos de um ano de estudo. Do outro lado, os resultados sugerem que na RM de Belo Horizonte, a diferença salarial entre os trabalhadores sem escolaridade e os com 15 anos ou mais de estudo é a menor, quando comparada às demais regiões metropolitanas (ver Tabela A2.1).

A Tabela A2.2 apresenta os resultados da estimação da equação dos aluguéis para cada uma das nove regiões metropolitanas incorporadas na análise.

Com base nos resultados, pode-se afirmar que os atributos dos imóveis incorporados no exame empírico apresentaram um bom poder de explicação para a formação do preço do aluguel nas regiões metropolitanas, chegando a explicar $70 \%$ do preço do aluguel na RM de Belém. Em adição, as variáveis explicativas incluídas nas equações de aluguéis, com poucas exceções, apresentaram uma significância a 5\%.

Os coeficientes das características estruturais dos imóveis, obtidos pela estimação da equação dos aluguéis para cada uma das nove regiões metropolitanas, apresentaram os sinais que conduzem a realidade do mercado de habitação das referidas regiões. Desse modo, há indicações de que, se o imóvel for um apartamento, o preço do aluguel é maior, quando comparado ao de uma casa ou um cômodo. Os resultados também sugerem que o número de banheiros que existe no imóvel, a quantidade de cômodos em geral e de cômodos que servem como dormitório, é positivamente correlacionado com o preço do aluguel do imóvel. Da mesma forma, o acesso aos serviços de esgoto e coleta de lixo tende a valorizar o preço do aluguel. Quanto às 
demais variáveis, como a densidade do imóvel (moradores por cômodos) e os bens que existem no domicílio, como telefone, máquina de lava roupa, microcomputador e geladeira, apenas foram incluídas para controlar pela heterogeneidade do custo de vida dentro da RM.

A respeito das diferenças observadas entre os coeficientes obtidos pela estimação da equação dos aluguéis para cada uma das regiões metropolitanas, vale apenas destacar a contribuição marginal significativamente maior do serviço de coleta de lixo, para a valoração do preço do imóvel na RM de Belo Horizonte e Porto Alegre, em relação às demais (ver Tabela A2.2).

\subsection{RANKING DA QUALIDADE DE VIDA DAS REGIÕES METROPOLITANAS BRASILEIRAS}

Com base nos coeficientes estimados da equação dos salários (equação 7) é previsto o salário que os trabalhadores receberiam se morassem em cada região metropolitana diferente da que mora. Da mesma forma, a partir da equação de aluguéis (equação 8) é estimado o aluguel que cada trabalhador teria que pagar por um imóvel com as mesmas características do imóvel que reside. Assim, pela comparação entre o salário que o individuo efetivamente recebe e o aluguel que ele paga, de um lado, com os salários e os preços dos aluguéis estimados, do outro, conforme descrito no item 4, é obtido o percentual de trabalhadores que teriam ganhos econômicos com a migração, aumento salarial e redução no preço do imóvel. Assim, de acordo com a medida proposta por Kahn (1995) e utilizada no artigo, quanto maior for esse percentual observado para uma localidade maior é o número de trabalhadores que devem ser compensados economicamente para morar nela, para compensar um menor consumo de amenidades (pior qualidade de vida) visando manter o seu nível de bem estar.

A primeira coluna da Tabela 1 apresenta o ranking obtido a partir da metodologia de Kahn (1995), e a segunda coluna apresenta o ranking estabelecido com base na extensão à metodologia de Kahn (1995) proposta por Silveira Neto, ambos estimados com base no salário nominal e no preço do aluguel nominal.

Desse modo, considerando inicialmente o ranking estabelecido com base em Kahn (1995), os resultados sugerem a seguinte ordenação da qualidade de vida para as principais regiões metropolitanas brasileiras: a RM de Belém seria a que tem a melhor qualidade de vida, em relação às demais, seguidas pelas RM de São Paulo, Rio de Janeiro, Recife, Salvador, Porto Alegre, Fortaleza, Curitiba e Belo Horizonte.

Em relação a esse resultado, como o ranking proposto por Kahn (1995), por hipótese, mensura a qualidade de todos os atributos locais que influenciam no bem estar dos 
trabalhadores, é difícil fazer previsões quanto à colocação das regiões metropolitanas no ranking. Entretanto, pode-se supor que, se o grau de desenvolvimento das regiões metropolitanas, o qual pode ser captado por indicadores de infraestrutura, saúde e educação, por exemplo, tiver uma importância maior para o bem-estar dos trabalhadores, relativo aos demais atributos locais que influenciam o bem-estar dos trabalhadores, como os de clima, por exemplo, deve-se esperar que as regiões metropolitanas localizadas nas regiões Sudeste e Sul fiquem mais bem colocadas no ranking, já que tais regiões são as que apresentam os maiores Índices de Desenvolvimento Humano (IDH), com base no último censo, em relação às regiões Norte e Nordeste $^{8}$.

Contudo, reconhece-se que a metodologia proposta por Kahn (1995) tem uma limitação por não considerar a influência de algumas amenidades para o custo de produção das firmas, como, por exemplo, a concentração de capital humano, que deve influenciar na produtividade do trabalho, tendendo a elevar o preço do aluguel nas regiões com alta concentração de capital humano, conforme o próprio autor reconhece. Dessa forma, também foi calculada a medida proposta por Silveira Neto (2006), a qual considera não apenas os trabalhadores que teriam um aumento no salário e redução no preço do aluguel advindos da migração, mais também aqueles com um ganho econômico líquido: o aumento no salário maior do que o aumento do preço do aluguel. Nesse caso, um resultado intuitivo seria que, ao considerar este último grupo de trabalhadores, as regiões com maiores dotações de capital humano, ou de outro atributo que venha a ter uma influência semelhante nos salários e nos aluguéis, alcancem melhores colocações no ranking obtidas com base em Kahn (1995), quando comparadas ao ranking estabelecido a partir da proposta de Silveira Neto (2006).

Em concordância a proposição acima referida, considerando que, entre as regiões metropolitanas consideradas no exame empírico, as RM de Porto Alegre, a RM de São Paulo e a RM do Rio de Janeiro, são as RM com os melhores indicadores de capital humano ${ }^{9}$, resulta que o índice de qualidade de vida proposto por Kahn (1995) pode superestimar a qualidade de vida oferecida pelas referidas regiões, relativo às outras RM incorporadas no exame.

\footnotetext{
${ }^{8}$ As regiões metropolitanas que estão localizadas nas regiões Sudeste e Sul são as que possuem os mais elevados IDH: a RM de Porto Alegre (IDH de 0,833) e a RM de São Paulo (IDH de 0,828) ocupam as primeiras colocações no ranking, o primeiro e segundo lugares, respectivamente; seguidas da RM de Curitiba (IDH de 0,824), da RM do Rio de Janeiro (IDH de 0,816), de Belo Horizonte (IDH de 0,811), de Belém (IDH de 0,797), de Salvador (IDH de 0,794), de Recife (IDH de 0,780) e de Fortaleza (IDH de 0,767).

${ }^{9}$ Para uma análise descritivas desses dados ver Rocha et. al. (2008)
} 
Assim sendo, comparando os dois rankings estabelecidos, com base em Kahn (1995) e Silveira Neto (2006), de fato a RM do Rio de Janeiro e a RM de São Paulo perdem colocações no ranking, quando considerado a extensão proposta por Silveira Neto (2006) (Tabela 1 - coluna 2). Contudo, a RM de Porto Alegre se manteve na sexta colocação nos dois rankings.

Tabela 1 - Ranking da qualidade de vida das regiões metropolitanas brasileiras, obtidos com base na abordagem da preferência revelada - salário nominal e aluguel nominal - 2006

\begin{tabular}{c|c|c|c}
\hline \multicolumn{2}{c|}{ Metodologia Kahn } & \multicolumn{2}{c}{ Metodologia Modificada Kahn (Silveira Neto) } \\
\hline IQV_Kahn & RM & IQV_Raul & RM \\
\hline $13 \%$ & Belém & $25 \%$ & Becife \\
\hline $16 \%$ & São Paulo & $27 \%$ & Fortaleza \\
\hline $19 \%$ & Rio de Janeiro & $29 \%$ & Salvador \\
\hline $20 \%$ & Recife & $33 \%$ & Rio de Janeiro \\
\hline $23 \%$ & Salvador & $38 \%$ & Porto Alegre \\
\hline $24 \%$ & Porto Alegre & $41 \%$ & Curitiba \\
\hline $25 \%$ & Fortaleza & $42 \%$ & Belo Horizonte \\
\hline $27 \%$ & Curitiba & $43 \%$ & São Paulo \\
\hline $34 \%$ & Belo Horizonte & $44 \%$ & \\
\hline
\end{tabular}

Fonte: Elaboração própria com base na PNAD-2006.

Levando em consideração que os centros urbanos são caracterizados por diferenças entre o custo de vida, também foi estabelecido um ranking considerando o salário real e o preço do aluguel real ${ }^{10}$. Em adição, foi estimada a equação de salários e aluguéis, a partir do salário nominal e do aluguel nominal, utilizando um filtro na amostra para captar apenas os trabalhadores com 40 horas ou mais de trabalho, com o objetivo de utilizar uma amostra de trabalhadores mais homogênea.

Os resultados da estimação das equações de salários e aluguéis a partir do salário real e do aluguel real estão reportados, em respectivo, na Tabela A2 e na Tabela A3 do apêndice em anexo. Assim como, os resultados das estimações utilizando o filtro para os trabalhadores com 40 horas de trabalho ou mais (Tabela A5 e Tabela A6).

A respeito do ranking da qualidade de vida calculado a partir do salário real e do preço do aluguel real para as regiões metropolitanas brasileiras, nota-se que a classificação obtida é bem próxima ao ranking estabelecido com base em Silveira Neto (2006). Esse resultado sugere que a extensão proposta por Silveira Neto (2006) de fato captura as diferenças no custo de vida entre as regiões metropolitanas, decorrente,

\footnotetext{
${ }^{10}$ Foram utilizados os índices de custo de vida de Azzoni et. al. (2003).
} 
por exemplo, pela concentração do capital humano. Dessa forma, esses resultados sugerem que a extensão proposta por Silveira Neto (2006) pode ser aplicada quando, em especial, se pretende captar a influência das diferenças no custo de vida entre as unidades geográficas de análise para a obtenção do ranking da qualidade de vida com base em Kahn (1995), e dados dos índices de custo de vida não são disponíveis para o pesquisador.

Tabela 2 - Ranking de qualidade de vida para as regiões metropolitanas brasileiras obtidos a partir do IQV de Kahn (1995), com base no salário real e aluguel real e para os trabalhadores com 40 horas ou mais de trabalho, 2006

\begin{tabular}{c|c|c|c}
\hline \multicolumn{2}{c|}{ Salário Real e Aluguel Real } & \multicolumn{2}{c}{$\begin{array}{c}\text { Filtro para os Trabalhadores com 40 horas } \\
\text { de Trabalho ou mais }\end{array}$} \\
\hline IQV_Kahn & RM & IQV_Kahn & RM \\
\hline $21 \%$ & Fortaleza & $21 \%$ & Belém \\
\hline $23 \%$ & Recife & $24 \%$ & Recife \\
\hline $41 \%$ & Belém & $26 \%$ & São Paulo \\
\hline $41 \%$ & Salvador & $27 \%$ & Rio de Janeiro \\
\hline $45 \%$ & Rio de Janeiro & $28 \%$ & Fortaleza \\
\hline $51 \%$ & Curitiba & $31 \%$ & Salvador \\
\hline $51 \%$ & Belo Horizonte & $35 \%$ & Curitiba \\
\hline $56 \%$ & Porto Alegre & $44 \%$ & Belo Horizonte \\
\hline $56 \%$ & São Paulo & $48 \%$ & \\
\hline
\end{tabular}

Fonte: Elaboração própria com base na PNAD-2006.

Quanto ao ranking estabelecido com o filtro para os trabalhadores com 40 horas de trabalho ou mais, comparando com o ranking obtido sem o filtro, observa-se uma variabilidade de uma colocação no ranking, da RM de São Paulo, RM de Rio de Janeiro, RM de Salvador e a RM de Porto Alegre; e de duas colocações, da RM de Fortaleza e da RM de Recife. A respeito dessas diferenças, da colocação das regiões metropolitanas nos rankings, pode ser indicativo de que a abordagem de Kahn (1995) é sensível à composição da amostra.

Por outro lado, deve-se reconhecer que, se alguma característica importante do trabalhador ou da ocupação do trabalho, que influência a remuneração do trabalho, não for incorporada para a determinação dos salários, o ranking estabelecido com base em Kahn (1995) pode não ser um bom indicador para comparar a qualidade de vida entre as regiões. A mesma limitação também pode estar presente na previsão dos gastos com os aluguéis. Dessa forma, a depender dos dados disponíveis das características dos trabalhadores e dos atributos dos imóveis, que o pesquisador pode observar, ou mesmo daqueles que o pesquisador julga importante para a previsão dos salários e aluguéis, pode haver variações nas posições das regiões metropolitanas nos rankings obtidos com base em Kahn (1995). 


\section{CONSIDERAÇÕES FINAIS}

Seguindo a linha dos estudos que objetivam valorar as amenidades urbanas, o presente artigo se propôs a aplicar uma abordagem, alternativamente a abordagem hedônica, buscando evitar os problemas econométricos que podem ser gerados pelo método hedônico. Dessa forma, a abordagem da preferência revelada com base em Kahn (2005) foi aplicada para ordenar as regiões metropolitanas quanto à qualidade de vida de vida por elas ofertada.

Pode-se dizer que a principal vantagem da abordagem de Kahn (2005) está na não dependência de dados de amenidades, dados esses que muitas vezes não são observados ou não estão disponíveis para o pesquisador. Assim sendo, se todo diferencial salarial e do custo de habitação que persistem entre as regióes são para compensar os trabalhadores por um menor consumo das amenidades locais, a medida proposta por Kahn (1995) pode ser aplicada para mensurar a qualidade de vida oferecida pelas regiões.

O ranking estabelecido com base em Kahn (1995), a partir do salário nominal e do aluguel nominal, indicou a seguinte ordenação das regiões metropolitanas com respeito à qualidade de vida: Belém, São Paulo, Rio de Janeiro, Recife, Salvador, Porto Alegre, Fortaleza, Curitiba, Belo Horizonte. Por outro lado, quando é considerado o custo de vida, utilizando o salário real e o preço do aluguel real, foi obtida a seguinte ordenação: Fortaleza, Recife, Belém, Salvador, Rio de Janeiro, Curitiba, Belo Horizonte, Porto Alegre, São Paulo.

Comparando o ranking calculado a partir do salário nominal e do preço do aluguel nominal ao obtido com base nos valores reais do salário e do preço do aluguel, observa-se que as duas regiões metropolitanas que tem os maiores custo de vida, a RM de São Paulo, centro econômico do país, e a RM de Rio de Janeiro, entre as consideradas na análise, caem na colocação no segundo ranking. Esse resultado sugere que a existência de diferencias entre os custos de vida das regióes podem influenciar no ranking da qualidade de vida estimado com base em Kahn (1995).

Porém, será que esses rankings realmente indicam diferenças entre a qualidade de vida das regiões metropolitanas brasileiras? Como a maioria dos índices que podem ser associados ao desenvolvido ou a qualidade de vida das regiões, como o índice de desenvolvimento humano, consideram na sua estimação, indicadores de renda, eles não são diretamente comparáveis ao índice proposto por Kanh (1995). Mas, considerando outros indicadores socio econômicos, como aqueles que mensuram a qualidade e cobertura dos serviços públicos e privados prestados (educação, segurança, saúde, lazer) e de infraestrutura, entre outros ${ }^{11}$, foi observado que as regiões metropolitanas do Sul e Sudeste são as que apresentam as melhores, quando comparadas as regiões

\footnotetext{
${ }^{11}$ Rocha e Matos (2010) fazem uma análise descritiva desses indicadores para as regiões metropolitanas brasileiras.
} 
metropolitanas do Norte e Nordeste. O ranking obtido aqui com base em Kahn (1995), a partir dos salários e aluguéis com seus valores nominais, é o que mais se aproxima dessas evidencias verificadas paras as regiões brasileiras. O estado de São Paulo e Rio de Janeiro com a segunda e terceira colocação no ranking, mas Porto Alegre ficou na sexta colocação e Curitiba na oitava, resultado esse que contradiz a afirmação acima.

Contudo, deve-se reconhecer que, se alguma característica importante do trabalhador ou da sua ocupação no trabalho, que influência a produtividade do trabalho, não for incorporada para a determinação dos salários, o ranking estabelecido com base em Kahn (1995) pode não ser um bom indicador para comparar a qualidade de vida entre as regiões. A mesma limitação também pode estar presente na previsão dos gastos com os aluguéis. Além disso, como o próprio Kahn (1995) reconhece, é possível que as localidades onde os trabalhadores apresentem um grau de escolaridade acima da média nacional tendam a ofertar salários mais elevados e um custo da habitação mais alto, e não necessariamente uma baixa qualidade de vida.

Porém, acredita-se que, mesmo sob essas limitações, o índice proposto por Kahn (1995) traz informações relevantes sobre os diferenciais salariais e do custo da habitação entre as localidades, que podem ser associados a diferenças entre os atributos das regionais. Mas, tal índice deve ser interpretado com cautela quando o objetivo for ordenar as regiões com respeito à qualidade de vida.

Como proposta para trabalhos futuros, pretende-se expandir essa análise utilizando os dados na forma de painel, com o objetivo de controlar pelas características não observáveis dos trabalhadores que influenciam o seu salário. Outro objetivo de pesquisa é testar se o ranking da qualidade de vida obtido para as regiões metropolitanas brasileiras com base em Kahn (1995) é condizente com outras abordagens que podem ser aplicadas para valorar as amenidades locais.

\section{REFERÊNCIAS}

AZZONI, C.; CARMO, H.; MENEZES, T. Comparação da paridade do poder de compra entre cidades: aspectos metodológicos e aplicação ao caso brasileiro. Pesquisa e Planejamento Econômico, IPEA, v. 33, n. 1, abril, 2003.

AZZONI, C.; SERVO, L. Education, cost of living and regional wage inequality in Brazil in the 90's. Papers in Regional Science, Alemanha, v. 81, p. 157-175, 2002.

COELHO, A. M.; CORSEUIL, C. H. Diferenciais salariais no Brasil: um breve panorama. In: CORSEUIL, G. H. (Ed.). Estrutura salarial: aspectos conceituais e novos resultados para o Brasil. Rio de Janeiro: IPEA, 2002, p. 67-100, 2002. Disponível em: <http://www.ipea.gov. br/sites/000/2/livros/estruturasalarial/capitulo3_diferenciais.pdf>. Acesso em: 25 fev. 2013. 
FAVERO, L. Preços hedônicos no mercado imobiliário comercial de São Paulo: a abordagem da modelagem multinível com classificação cruzada. Estudos Econômicos, USP, v. 41, p. 777$810,2011$.

HERMANN, B.; HADDAD, E. Mercado imobiliário e amenidades: a view through the window. Estudos Econômicos, USP, São Paulo, v. 35, n. 2, p. 237-269, 2005.

HOX, J. J. Applied multilevel analysis. 2 ed. Amsterdam: TT-Publikaties, 1995. Disponível em: $<$ http://igitur-archive.library.uu.nl/fss/2007-1114-201211/hox_95_applied\%20multilevel\%20 analysis.pdf $>$. Acesso em: 25 fev. 2013.

KAHN, M. A revealed preference approach for ranking city quality life. Journal of Urban Economics, v. 38, p. 221-235, 1995.

KAHNEMAN, D. Experienced utility and objective happiness: A moment-based approach. In: KAHNEMAN, D; TVERSKY, A. (Eds.) Choices, values, and frames. New York: Cambridge University Press, p. 673-692, 2000.

MONTE, D. The amenity cost of marginal climate change: the case of Brazil. Paper of Discussion, Yale University, June, 2004.

RAUCH, J. Productivity gains from geographic concentration of human capital: evidence from the cities. Journal of Urban Economics, v. 34, n. 3, p. 380-400, 1993.

ROBACK, J. The value of local urban amenities: theory and measurement. Ph.D. Dissertation, University of Rochester, 1980.

ROBACK, J. Wages, rents and the quality of life. Journal of Political Economic, v. 90, n. 6, December, p. 1.257-1.278, 1982.

ROCHA, R.; MAGALHÃES, A. As amenidades naturais influenciam a escolha locacional dos trabalhadores? Evidências para as regiões metropolitanas brasileiras. Revista Brasileira de Estudos de População, v. 28, n. 2, p. 369-387, 2011.

ROCHA, R.; MAGALHÃES, A. Uma análise exploratória das disparidades naturais, sociais e econômicas que caracterizam as regiões metropolitanas brasileiras. Economia e Desenvolvimento, Recife, v. 8, p. 252-295, 2009.

ROSEN, S. Hedonic prices and implicit markets: product differentiation in pure competition. Journal Political Economic, v. 82, n. 1, January/February, p. 34-55, 1974.

ROSEN, S. On a wage based index of urban quality of life. In: MIESZKOWSKI, P.; STRASSHEIM, M. (Eds.) Studies in urban economics. Vol. II. Baltimore: John Hopkins University Press, p. 74-104, 1979.

SILVEIRA NETO, R. Preferência revelada e arbitragem espacial: determinando um ranking de qualidade de vida para as regiões metropolitanas do Brasil. In: Encontro Regional de Economia, 11, 2006, Fortaleza. Anais. Fortaleza: Banco do Nordeste, 2006.

SILVEIRA NETO, R.; AZZONI, C. Disparidades regionais de renda no brasil: qual o papel das amenidades? In: Encontro Regional de Economia - ANPEC Nordeste, 9, 2004, Fortaleza. Anais. Fortaleza: ANPEC, 2004. 


\section{APÊNDICE 1 - ÍNDICE DE QUALIDADE DE VIDA (ROBACK, 1982)}

Para mensurar a qualidade de vida (IQV) das localidades, Roback (1982), propõe uma medida que é o resultado do somatório entre a multiplicação do preço implícito de cada atributo local (ou propensão marginal a pagar), $f z$, pelo nível do respectivo atributo em cada localidade $j$ na forma:

$$
I Q V_{j}=\sum_{k} f z_{k} z_{k j}
$$

onde os atributos locais estão indexados por $k$ e a função de preço implícito, obtidos pela condição de equilíbrio imposta ao mercado de trabalho - situação que trabalhadores não tem ganhos de bem-estar com a migração - são dados por:

$$
f_{z}=\frac{V z}{V w}=\frac{d p}{d z}-\frac{d w}{d z}
$$

onde as diferenças do salário e do aluguel com respeito a cada atributo local considerado no exame empírico, $d w / d z$ e $d p / d z$, são obtidas pela estimação das seguintes equações:

$$
w_{i j}=\beta_{0}+X_{i} \beta_{1}+Z_{j} \beta_{2}+u_{i j}
$$

onde $w_{i j}$ é o salário que o indivíduo $i$ recebe na localidade $j ; X_{i}$ é um vetor das características individuais dos trabalhadores e da ocupação dos trabalhadores; $Z_{j}$ é o vetor dos atributos locais; e $u_{i j}$ é o erro estocástico.

De forma semelhante, o preço do aluguel é regredido em função dos atributos do imóvel e dos atributos locais:

$$
r_{i j}=\theta_{0}+Q_{i} \theta_{1}+Z_{j} \theta_{2}+v_{i j}
$$

onde $r_{i j}$ é o aluguel pago pelo indivíduo $i$ na localidade $j ; Q_{i}$ é o vetor das características estruturais do imóvel; $Z_{j}$ é o vetor dos atributos locais; e $v_{i j}$ é o erro estocástico.

O IQV é a soma da dotação dos $k$ atributos locais da localidade $j$, ponderados pelas respectivas funções de preço implícito $(f)$, a qual mensura as preferências dos trabalhadores pelos atributos locais. Assim, quanto maior for o IQV da localidade $j$, maior é a qualidade das amenidades de $j$, em relação às demais $j$ localidades incluídas para computar o IQV. 
APÊNDICE 2

Tabela A2.1 - Resultados da estimação da equação de salários (equação 7) para cada uma das regiões metropolitanas -2006

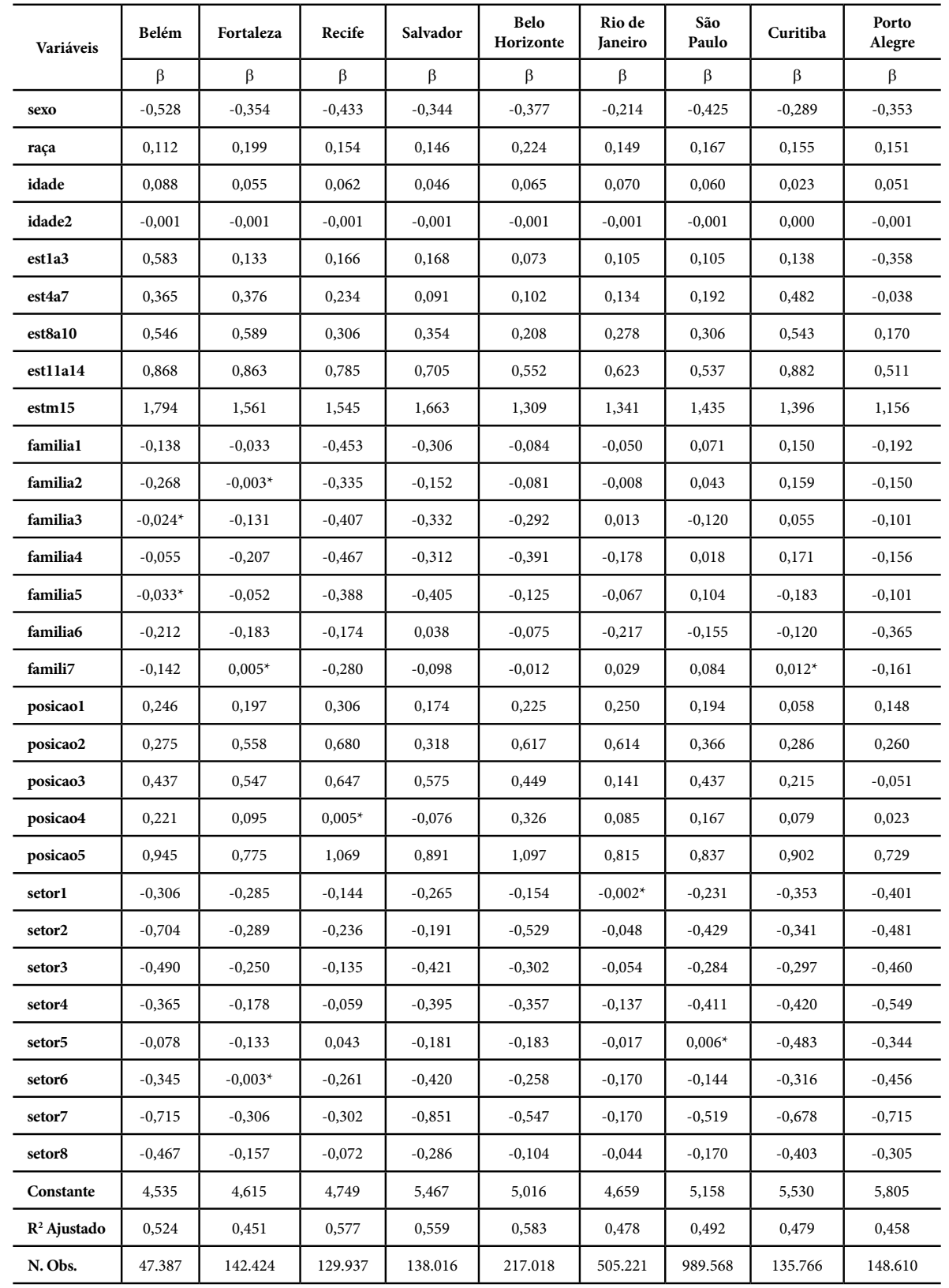

Nota: $\left({ }^{*}\right)$ Valores estatisticamente não significantes a menos de $5 \%$. Todos os demais coeficientes são significantes a menos de $5 \%$. Fonte: Elaboração própria com base na PNAD-2006. 
Tabela A2.2 - Resultados da estimação das equações de aluguéis (equação 8) para as regiões metropolitanas - 2006

\begin{tabular}{|c|c|c|c|c|c|c|c|c|c|}
\hline Variáveis & Belém & Fortaleza & Recife & Salvador & $\begin{array}{c}\text { Belo } \\
\text { Horizonte }\end{array}$ & $\begin{array}{l}\text { Rio de } \\
\text { Janeiro }\end{array}$ & $\begin{array}{c}\text { São } \\
\text { Paulo }\end{array}$ & Curitiba & $\begin{array}{l}\text { Porto } \\
\text { Alegre }\end{array}$ \\
\hline & $\beta$ & $\beta$ & $\beta$ & $\beta$ & $\beta$ & $\beta$ & $\beta$ & $\beta$ & $\beta$ \\
\hline morcom & 0,009 & 0,018 & 0,057 & 0,050 & 0,029 & 0,058 & 0,038 & 0,046 & 0,040 \\
\hline ncomo & 0,150 & 0,068 & 0,044 & 0,036 & 0,072 & 0,069 & 0,118 & 0,033 & 0,064 \\
\hline fone & 0,199 & 0,143 & 0,193 & 0,102 & 0,119 & 0,134 & 0,135 & 0,141 & 0,144 \\
\hline lavaroupa & 0,091 & 0,088 & 0,212 & 0,183 & 0,105 & 0,083 & 0,194 & 0,113 & 0,110 \\
\hline microcom & 0,189 & 0,217 & 0,118 & 0,263 & 0,199 & 0,183 & 0,155 & 0,208 & 0,059 \\
\hline nbanheiro & 0,023 & 0,165 & 0,169 & 0,252 & 0,156 & 0,156 & 0,059 & 0,318 & 0,169 \\
\hline lixo & 0,147 & $0,006^{*}$ & 0,162 & 0,126 & 0,334 & 0,077 & 0,051 & 0,049 & 0,253 \\
\hline esgoto & 0,167 & 0,165 & 0,096 & 0,142 & 0,179 & 0,159 & 0,178 & 0,084 & $-0,005^{\star}$ \\
\hline Constante & 4,485 & 4,215 & 4,156 & 4,246 & 4,142 & 4,563 & 4,334 & 4,498 & 4,665 \\
\hline $\mathbf{R}^{2}$ Ajustado & 0,702 & 0,593 & 0,634 & 0,682 & 0,655 & 0,611 & 0,615 & 0,608 & 0,557 \\
\hline
\end{tabular}

Nota: $\left({ }^{*}\right)$ Valores estatisticamente não significantes a menos de $5 \%$. Todos os demais coeficientes são significantes a menos de $5 \%$. Fonte: Elaboração própria com base na PNAD-2006. 
Tabela A2.3 - Resultados das estimações das equações de salários (equação 7) para as regiões metropolitanas a partir do salário real - 2006

\begin{tabular}{|c|c|c|c|c|c|c|c|c|c|}
\hline Variáveis & Belém & Fortaleza & Recife & Salvador & $\begin{array}{c}\text { Belo } \\
\text { Horizonte }\end{array}$ & $\begin{array}{l}\text { Rio de } \\
\text { Janeiro }\end{array}$ & $\begin{array}{c}\text { São } \\
\text { Paulo }\end{array}$ & Curitiba & $\begin{array}{l}\text { Porto } \\
\text { Alegre }\end{array}$ \\
\hline raça & 0,112 & 0,199 & 0,154 & 0,146 & 0,224 & 0,149 & 0,167 & 0,155 & 0,151 \\
\hline sexo & $-0,528$ & $-0,354$ & $-0,433$ & $-0,344$ & $-0,377$ & $-0,214$ & $-0,425$ & $-0,289$ & $-0,353$ \\
\hline idade & 0,088 & 0,055 & 0,062 & 0,046 & 0,065 & 0,070 & 0,060 & 0,023 & 0,051 \\
\hline idade2 & $-0,001$ & $-0,001$ & $-0,001$ & $-0,001$ & $-0,001$ & $-0,001$ & $-0,001$ & 0,000 & $-0,001$ \\
\hline est1a3 & 0,583 & 0,133 & 0,166 & 0,168 & 0,073 & 0,105 & 0,105 & 0,138 & $-0,358$ \\
\hline est4a7 & 0,365 & 0,376 & 0,234 & 0,091 & 0,102 & 0,134 & 0,192 & 0,482 & $-0,038$ \\
\hline est8a10 & 0,546 & 0,589 & 0,306 & 0,354 & 0,208 & 0,278 & 0,306 & 0,543 & 0,170 \\
\hline est11a14 & 0,868 & 0,863 & 0,785 & 0,705 & 0,552 & 0,623 & 0,537 & 0,882 & 0,511 \\
\hline estm15 & 1,794 & 1,561 & 1,545 & 1,663 & 1,309 & 1,341 & 1,435 & 1,396 & 1,156 \\
\hline familial & $-0,138$ & $-0,033$ & $-0,453$ & $-0,306$ & $-0,084$ & $-0,050$ & 0,071 & 0,150 & $-0,192$ \\
\hline familia2 & $-0,268$ & $-0,003$ & $-0,335$ & $-0,152$ & $-0,081$ & $-0,008$ & 0,043 & 0,159 & $-0,150$ \\
\hline familia3 & $-0,024$ & $-0,131$ & $-0,407$ & $-0,332$ & $-0,292$ & 0,013 & $-0,120$ & 0,055 & $-0,101$ \\
\hline familia4 & $-0,055$ & $-0,207$ & $-0,467$ & $-0,312$ & $-0,391$ & $-0,178$ & 0,018 & 0,171 & $-0,156$ \\
\hline familia5 & $-0,033$ & $-0,052$ & $-0,388$ & $-0,405$ & $-0,125$ & $-0,067$ & 0,104 & $-0,183$ & $-0,101$ \\
\hline familia6 & $-0,212$ & $-0,183$ & $-0,174$ & 0,038 & $-0,075$ & $-0,217$ & $-0,155$ & $-0,120$ & $-0,365$ \\
\hline familia7 & $-0,142$ & 0,005 & $-0,280$ & $-0,098$ & $-0,012$ & 0,029 & 0,084 & 0,012 & $-0,161$ \\
\hline posicaol & 0,246 & 0,197 & 0,306 & 0,174 & 0,225 & 0,250 & 0,194 & 0,058 & 0,148 \\
\hline posicao2 & 0,275 & 0,558 & 0,680 & 0,318 & 0,617 & 0,614 & 0,366 & 0,286 & 0,260 \\
\hline posicao3 & 0,437 & 0,547 & 0,647 & 0,575 & 0,449 & 0,141 & 0,437 & 0,215 & $-0,051$ \\
\hline posicao4 & 0,221 & 0,095 & 0,005 & $-0,076$ & 0,326 & 0,085 & 0,167 & 0,079 & 0,023 \\
\hline posicao5 & 0,945 & 0,775 & 1,069 & 0,891 & 1,097 & 0,815 & 0,837 & 0,902 & 0,729 \\
\hline setor1 & $-0,306$ & $-0,285$ & $-0,144$ & $-0,265$ & $-0,154$ & $-0,002$ & $-0,231$ & $-0,353$ & $-0,401$ \\
\hline setor2 & $-0,704$ & $-0,289$ & $-0,236$ & $-0,191$ & $-0,529$ & $-0,048$ & $-0,429$ & $-0,341$ & $-0,481$ \\
\hline setor3 & $-0,490$ & $-0,250$ & $-0,135$ & $-0,421$ & $-0,302$ & $-0,054$ & $-0,284$ & $-0,297$ & $-0,460$ \\
\hline setor4 & $-0,365$ & $-0,178$ & $-0,059$ & $-0,395$ & $-0,357$ & $-0,137$ & $-0,411$ & $-0,420$ & $-0,549$ \\
\hline setor5 & $-0,078$ & $-0,133$ & 0,043 & $-0,181$ & $-0,183$ & $-0,017$ & 0,006 & $-0,483$ & $-0,344$ \\
\hline setor6 & $-0,345$ & $-0,003$ & $-0,261$ & $-0,420$ & $-0,258$ & $-0,170$ & $-0,144$ & $-0,316$ & $-0,456$ \\
\hline setor7 & $-0,715$ & $-0,306$ & $-0,302$ & $-0,851$ & $-0,547$ & $-0,170$ & $-0,519$ & $-0,678$ & $-0,715$ \\
\hline setor8 & $-0,467$ & $-0,157$ & $-0,072$ & $-0,286$ & $-0,104$ & $-4,39 \mathrm{E}-0$ & $-0,17$ & $-0,403$ & $-0,305$ \\
\hline Constante & 4,612 & 4,704 & 4,874 & 5,536 & 5,034 & 4,606 & 5,056 & 5,508 & 5,782 \\
\hline $\mathbf{R}^{2}$ Ajust. & 0,524 & 0,451 & 0,577 & 0,558 & 0,583 & 0,4678 & 0,492 & 0,479 & 0,458 \\
\hline N. Obs. & 47.387 & 142.424 & 129.937 & 138.016 & 217.018 & 505.221 & 989.568 & 135.766 & 148.61 \\
\hline
\end{tabular}

Nota: $\left(^{*}\right)$ Valores estatisticamente não significantes a menos de $5 \%$ de significância. Todos os demais coeficientes são significantes a menos de $5 \%$. Fonte: Elaboração própria. 
Tabela A2.4 - Resultados das estimações das equações de aluguéis (equação 8) para as regiões metropolitanas a partir do aluguel real - 2006

\begin{tabular}{l|c|c|c|c|c|c|c|c|c}
\hline \multicolumn{1}{|c|}{ Variáveis } & Belém & Fortaleza & Recife & Salvador & $\begin{array}{c}\text { Belo } \\
\text { Horizonte }\end{array}$ & $\begin{array}{c}\text { Rio de } \\
\text { Janeiro }\end{array}$ & $\begin{array}{c}\text { São } \\
\text { Paulo }\end{array}$ & Curitiba & $\begin{array}{c}\text { Porto } \\
\text { Alegre }\end{array}$ \\
\hline Morcom & 0,009 & 0,018 & 0,057 & 0,050 & 0,029 & 0,058 & 0,038 & 0,046 & 0,040 \\
\hline Ncomo & 0,150 & 0,068 & 0,044 & 0,036 & 0,072 & 0,069 & 0,118 & 0,033 & 0,064 \\
\hline Ndorm & 0,022 & 0,000 & 0,093 & 0,101 & 0,043 & 0,074 & 0,040 & 0,051 & 0,095 \\
\hline fone & 0,199 & 0,143 & 0,193 & 0,102 & 0,119 & 0,134 & 0,135 & 0,141 & 0,144 \\
\hline lavaroupa & 0,091 & 0,088 & 0,212 & 0,183 & 0,105 & 0,083 & 0,194 & 0,113 & 0,110 \\
\hline microco & 0,189 & 0,217 & 0,118 & 0,263 & 0,199 & 0,183 & 0,155 & 0,208 & 0,059 \\
\hline geladeira & 0,188 & 0,252 & 0,197 & 0,207 & 0,058 & 0,223 & 0,235 & 0,187 & 0,019 \\
\hline napart & $-0,345$ & $-0,194$ & $-0,251$ & $-0,252$ & $-0,228$ & $-0,340$ & $-0,052$ & $-0,266$ & $-0,327$ \\
\hline nbanheiro & 0,023 & 0,165 & 0,169 & 0,252 & 0,156 & 0,156 & 0,059 & 0,318 & 0,169 \\
\hline lixo & 0,147 & 0,006 & 0,162 & 0,126 & 0,334 & 0,077 & 0,051 & 0,049 & 0,253 \\
\hline esgoto & 0,167 & 0,165 & 0,096 & 0,142 & 0,179 & 0,159 & 0,178 & 0,084 & $-0,005$ \\
\hline Constante & 4,562 & 4,303 & 4,282 & 4,314 & 4,160 & 4,510 & 4,231 & 4,476 & 4,642 \\
\hline $\mathbf{R}^{2}$ Ajust. & 0,702 & 0,593 & 0,634 & 0,682 & 0,655 & 0,611 & 0,615 & 0,608 & 0,557 \\
\hline $\mathbf{N}$. Obs. & 47.387 & 142.424 & 129.937 & 138.016 & 217.018 & 505.221 & 989.568 & 135.766 & 148.61 \\
\hline
\end{tabular}

Nota: $\left({ }^{*}\right)$ Valores estatisticamente não significantes a menos de $5 \%$ de significância. Todos os demais coeficientes são significantes a menos de $5 \%$. Fonte: Elaboração própria. 
Tabela A2.5 - Resultados das estimações das equações de salários (equação 7) para as regiões metropolitanas com filtro com 40 horas ou mais de trabalho - 2006

\begin{tabular}{|c|c|c|c|c|c|c|c|c|c|}
\hline Variáveis & Belém & Fortaleza & Recife & Salvador & $\begin{array}{c}\text { Belo } \\
\text { Horizonte }\end{array}$ & $\begin{array}{l}\text { Rio de } \\
\text { Janeiro }\end{array}$ & $\begin{array}{c}\text { São } \\
\text { Paulo }\end{array}$ & Curitiba & $\begin{array}{l}\text { Porto } \\
\text { Alegre }\end{array}$ \\
\hline sexo & 0,126 & 0,145 & 0,152 & 0,123 & 0,237 & $-0,111$ & $-0,340$ & $-0,218$ & $-0,282$ \\
\hline raça & $-0,327$ & $-0,229$ & $-0,428$ & $-0,314$ & $-0,377$ & $-0,166$ & 0,025 & $-0,301$ & $-0,425$ \\
\hline idade & 0,038 & 0,046 & 0,056 & 0,042 & 0,044 & 0,179 & 0,163 & 0,184 & 0,178 \\
\hline idade2 & 0,000 & 0,000 & $-0,001$ & 0,000 & 0,000 & 0,138 & 0,121 & 0,065 & $-0,250$ \\
\hline est1a3 & 0,370 & 0,060 & 0,113 & $0,0216^{*}$ & 0,024 & 0,059 & 0,045 & 0,022 & 0,039 \\
\hline est4a7 & 0,356 & 0,210 & 0,165 & $-0,002^{*}$ & 0,044 & $-0,001$ & 0,000 & 0,000 & 0,000 \\
\hline est8a10 & 0,450 & 0,409 & 0,232 & 0,237 & 0,213 & 0,193 & 0,179 & 0,414 & $-0,056$ \\
\hline est11a14 & 0,805 & 0,645 & 0,670 & 0,594 & 0,472 & 0,323 & 0,300 & 0,470 & 0,119 \\
\hline estm15 & 1,723 & 1,287 & 1,477 & 1,595 & 1,317 & 0,684 & 0,589 & 0,808 & 0,441 \\
\hline familial & 0,078 & $-0,101$ & $-0,449$ & $-0,296$ & $-0,181$ & 1,473 & 1,450 & 1,312 & 1,056 \\
\hline familia2 & $-0,119$ & $0,0035^{\star}$ & $-0,325$ & $-0,162$ & $-0,110$ & 0,019 & 0,115 & 0,132 & $-0,193$ \\
\hline familia3 & 0,207 & $-0,031$ & $-0,436$ & $-0,293$ & $-0,191$ & 0,053 & 0,119 & 0,180 & $-0,173$ \\
\hline familia4 & $-0,080$ & $-0,264$ & $-0,353$ & $-0,167$ & $-0,272$ & 0,060 & $-0,095$ & $-0,016$ & $-0,124$ \\
\hline familia5 & 0,113 & 0,024 & $-0,417$ & $-0,357$ & $-0,190$ & $-0,083$ & 0,070 & 0,176 & $-0,208$ \\
\hline familia6 & $-0,138$ & $-0,062$ & $-0,213$ & 0,084 & $-0,218$ & $-0,037$ & 0,092 & $-0,344$ & $-0,154$ \\
\hline familia7 & $-0,047$ & $-0,034$ & $-0,318$ & $-0,100$ & $-0,070$ & $-0,243$ & $-0,108$ & $-0,380$ & $-0,181$ \\
\hline posicaol & 0,187 & 0,206 & 0,267 & 0,136 & 0,153 & 0,104 & 0,170 & 0,020 & $-0,188$ \\
\hline posicao 2 & 0,329 & 0,568 & 0,681 & 0,111 & 0,495 & 0,186 & 0,163 & 0,019 & 0,060 \\
\hline posicao3 & 0,155 & 0,484 & 0,296 & 0,372 & 0,129 & 0,479 & 0,527 & 0,264 & 0,114 \\
\hline posicao4 & 0,278 & 0,141 & 0,101 & 0,024 & 0,282 & $-0,062$ & 0,068 & $-0,427$ & 0,104 \\
\hline posicao5 & 0,982 & 0,750 & 1,025 & 0,945 & 0,943 & 0,128 & 0,249 & 0,203 & 0,066 \\
\hline setor1 & $-0,343$ & $-0,314$ & $0,0107^{*}$ & $-0,384$ & $-0,252$ & 0,856 & 0,856 & 0,749 & 0,660 \\
\hline setor2 & $-0,755$ & $-0,431$ & $-0,147$ & $-0,298$ & $-0,624$ & $-0,064$ & 0,020 & $-0,350$ & $-0,492$ \\
\hline setor3 & $-0,531$ & $-0,345$ & 0,042 & $-0,564$ & $-0,335$ & $-0,095$ & $-0,205$ & $-0,415$ & $-0,569$ \\
\hline setor4 & $-0,384$ & $-0,347$ & 0,085 & $-0,583$ & $-0,362$ & $-0,155$ & $-0,079$ & $-0,342$ & $-0,531$ \\
\hline setor5 & $-0,183$ & $-0,180$ & 0,166 & $-0,321$ & $-0,263$ & $-0,282$ & $-0,269$ & $-0,459$ & $-0,663$ \\
\hline setor6 & $-0,493$ & 0,022 & 0,055 & $-0,500$ & $-0,364$ & $-0,127$ & 0,188 & $-0,382$ & $-0,400$ \\
\hline setor7 & $-0,714$ & $-0,424$ & 0,141 & $-0,865$ & $-0,346$ & $-0,090$ & 0,083 & $-0,339$ & $-0,411$ \\
\hline setor8 & $-0,348$ & $-0,194$ & 0,066 & $-0,433$ & $-0,126$ & $-0,207$ & $0,00597^{*}$ & $-0,131$ & $-0,883$ \\
\hline Constante & 5,296 & 5,030 & 4,861 & 5,769 & 5,634 & 4,776 & 5,134 & 5,636 & 6,205 \\
\hline $\mathbf{R}^{2}$ Ajust. & 0,548 & 0,457 & 0,569 & 0,583 & 0,587 & 0,523 & 0,495 & 0,508 & 0,449 \\
\hline N. Obs. & 37.333 & 117.048 & 106.019 & 110.844 & 181.961 & 416.140 & 868.340 & 116.999 & 127.693 \\
\hline
\end{tabular}

Nota: ${ }^{*}$ ) Valores estatisticamente não significantes a menos de $5 \%$ de significância. Todos os demais coeficientes são significantes a menos de $5 \%$. Fonte: Elaboração própria. 
Tabela A2.6 - Resultados das estimações das equações de aluguéis (equação 8) para as regiões metropolitanas com filtro com 40 horas ou mais de trabalho - 2006

\begin{tabular}{l|c|c|c|c|c|c|c|c|c}
\hline Variáveis & Belém & Fortaleza & Recife & Salvador & $\begin{array}{c}\text { Belo } \\
\text { Horizonte }\end{array}$ & $\begin{array}{c}\text { Rio de } \\
\text { Janeiro }\end{array}$ & $\begin{array}{c}\text { São } \\
\text { Paulo }\end{array}$ & Curitiba & $\begin{array}{c}\text { Porto } \\
\text { Alegre }\end{array}$ \\
\hline morcom & $0,004^{*}$ & 0,024 & 0,057 & 0,055 & 0,027 & 0,055 & 0,035 & 0,057 & 0,091 \\
\hline ncomo & 0,220 & 0,153 & 0,199 & 0,095 & 0,111 & 0,057 & 0,036 & 0,042 & 0,030 \\
\hline ndorm & 0,069 & 0,082 & 0,203 & 0,166 & 0,108 & 0,138 & 0,142 & 0,113 & 0,137 \\
\hline fone & 0,207 & 0,211 & 0,109 & 0,225 & 0,175 & 0,080 & 0,190 & 0,116 & 0,114 \\
\hline lavaroupa & 0,165 & 0,220 & 0,161 & 0,233 & 0,011 & 0,163 & 0,152 & 0,193 & 0,031 \\
\hline microcom & $-0,360$ & $-0,180$ & $-0,250$ & $-0,258$ & $-0,222$ & 0,283 & 0,184 & 0,193 & $0,0007^{*}$ \\
\hline geladeira & 0,018 & 0,157 & 0,189 & 0,276 & 0,162 & $-0,317$ & $-0,054$ & $-0,292$ & $-0,373$ \\
\hline napart & 0,164 & 0,028 & 0,149 & 0,110 & 0,373 & 0,152 & 0,048 & 0,358 & 0,135 \\
\hline nbanheiro & 0,161 & 0,136 & 0,097 & 0,210 & 0,164 & 0,088 & 0,038 & 0,039 & 0,172 \\
\hline lixo & 0,146 & 0,072 & 0,033 & 0,024 & 0,067 & 0,170 & 0,183 & 0,114 & 0,044 \\
\hline esgoto & 0,018 & 0,006 & 0,090 & 0,103 & 0,068 & 0,079 & 0,118 & 0,038 & 0,075 \\
\hline Constante & 4,523 & 4,179 & 4,251 & 4,213 & 4,153 & 4,470 & 4,422 & 4,450 & 4,801 \\
\hline $\mathbf{R}^{2}$ Ajust. & 0,688 & 0,601 & 0,612 & 0,684 & 0,654 & 0,607 & 0,598 & 0,622 & 0,558 \\
\hline $\mathbf{N}$. Obs. & 37.333 & 106.019 & 181.961 & 117.048 & 110.844 & 416.140 & 868.340 & 116.999 & 127.693 \\
\hline
\end{tabular}

Nota: ( $\left.{ }^{*}\right)$ Valores estatisticamente não significantes a menos de $5 \%$ de significância. Todos os demais coeficientes são significantes a menos de $5 \%$. Fonte: Elaboração própria. 